http://jmscr.igmpublication.org/home/ ISSN (e)-2347-176x ISSN (p) 2455-0450

crossref DOI: https://dx.doi.org/10.18535/jmscr/v9i12.28

\title{
Basal Cell Carcinoma (BCC) of Nose, Impact of three field Technique Radiotherapy- A Case Report !
}

\author{
Author \\ Vivek Kumar Pandey ${ }^{1}$, S.N.Prasad ${ }^{2}$, M.Q.Baig ${ }^{3 *}$, Jitendra Kumar Verma ${ }^{4}$, \\ Pramod Kumar Singh ${ }^{5}$, Archana Singh ${ }^{6}$, Ansu Goel ${ }^{7}$, Mohd Waseem Raza ${ }^{8}$ \\ ${ }^{1}$ Junior resident third year, ${ }^{2}$ Director J.K Cancer Institute, ${ }^{3}$ Associate Professor, ${ }^{4}$ Assistant Professor, \\ ${ }^{5}$ Assistant Professor, ${ }^{6}$ Assistant Professor, ${ }^{7}$ Assistant Professor, ${ }^{8}$ Assistant Professor \\ J.K Cancer Institute Kanpur \\ *Corresponding Author \\ Major Retd M.Q. Baig
}

\begin{abstract}
The reported incidence of skin cancer in India is $1 \%$ of all the cancers. Basal cell carcinoma is a type of skin cancer begins in the basal cell with in the skin a type of cell that produces new skin cells as old one die. Majority of skin cancer either basal cell carcinoma or squamous cell carcinoma. Basal cell carcinoma is as common as squamous cell carcinoma of skin but lymph node involvement in basal cell carcinoma is rare. Henceforth main stay of treatment of BCC remains as local treatment. There are five variety of BCC like, Nodular, Nodular ulcerative (commonly head and neck site), Rodent ulcer, Pigmented type, superficial type pigmented variety closely mimic melanoma of skin cancer. The existing literature on BCC in India is scant, so in this case study we were intended about the radiotherapy techniques for BCC in order to give full dose of radiation and to find result out of that very techniques.
\end{abstract}

Keywords: BCC, Radiotherapy.

\section{Case Summary}

A 66 years old male from Gorakhpur UP came with chief complain of exophytic growth over nose since last 10 years with size $>4.5 \mathrm{~cm}$ black proliferative lesion which was histologically proven Basal cell carcinoma.

CT PNS \& NECK (pre treatment) was done which showed exophytic lesion from skin of nose, involving subcutaneous tissue and alar cartilage of nose extension to the pre maxillary surface of skin of right side. Bony erosion was absent. On examination to nasal cavity extension to nasal cavity was found absent. On immunohistochemistry findings were as given below:

1. P40- positive (strongly)

2. AR- positive (occasionally)

3. CK 7 -negative

4. Berp4-negative 


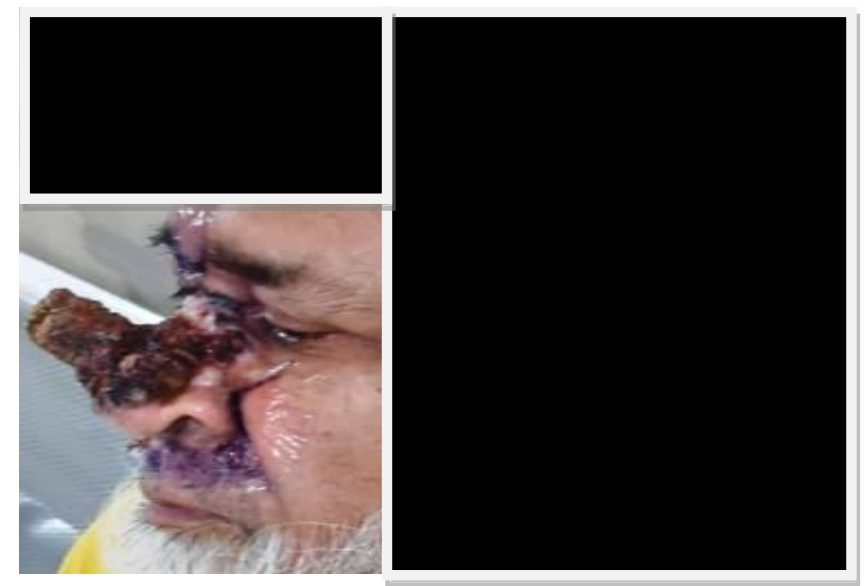

Figure-1 Pretreatment Picture BCC, with horn on nose

Past treatment history- Underwent angioplasty 8 years back and on antihypertensive medication since 10 years

Treatment - Although commonly single field are appropriate for vast majority of skin cancers present on face nose etc. Dose usually given 45Gy in 10 fractions or we can go up to the $50 \mathrm{gy}$ in 10 fractions if tumor size is more than $2 \mathrm{~cm}$ in size. After complete clinical examination and all relevant investigation, patient was planned for radiation therapy by 3 field tech. to involved area of face with cotton bolus and both eye block used. Along given below three field technique of Radiotherapy treatment has been delivered.

1. Anterior field with $0.5 \mathrm{~cm}$ depth

2. Right lateral field with $0,5 \mathrm{~cm}$ depth

3. Left lateral field with $0.5 \mathrm{~cm}$ depth

Dose - Phase 1-EBRT/CO60/45GY/10\#/450CGY PER \#/5 \# PER Week /3 Field to face

Phase 2-EBRT /CO60/5GY/1\#/1 field (single anterior field )

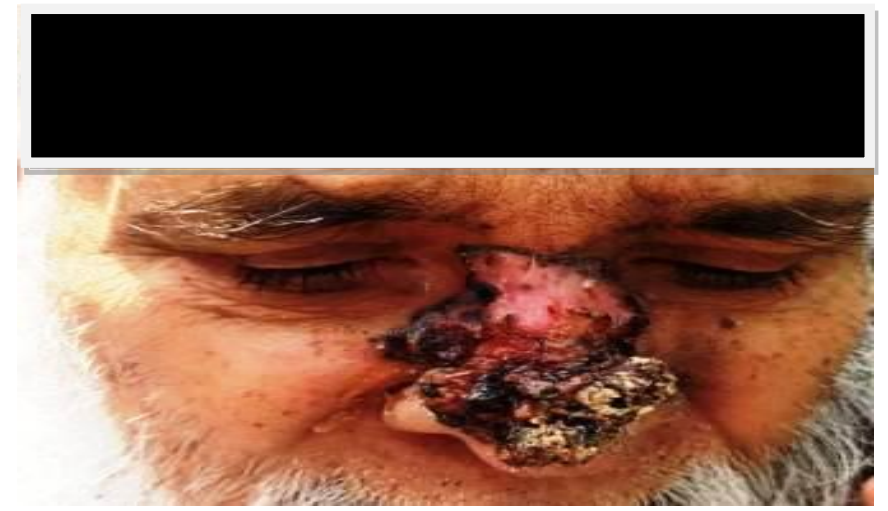

Figure-2 Post treatment just after 2 weeks completion of radiotherapy, horn dropped out.
Till now radiation therapy has been completed, last radiation therapy was given on 12 November 2021. Now the patient is been monitored on regular basis of follow-up for assessment of response to given treatment.

\section{Discussion}

In the radiotherapy treatment of BCC Skin cancer one should keep given below points in their mind before jumping to start radiotherapy treatment-

1) Radiotherapy is usually indicated when bcc is found on face, nose, lip and eyelid where surgery is technically difficult as well as leads to poor cosmetic out come.

2) Generally when skin tumor involves underline cartilage or bone radiotherapy should be avoided and surgery should be preferred.

3) Radiotherapy is indicated in condition when post op margin is positive.

4) Smaller lesion mould treatment or interstitial treatment implant may be considered, skin cancer can also be treated by electron treatment with good results.

\section{Conclusions}

Definitive Radiotherapy is useful for treating early-stage skin cancers where resection would result in a significant cosmetic and/or functional deficit. Postoperative Radiotherapy is indicated in situations where the probability of residual disease after surgery is high and the chance of successful salvage is modest. Patients with parotid-area node metastases are optimally treated with surgery and postoperative RT.

\section{References}

1. R. Rossi, P. Campolmi, B. Gnome, D. Massi, and P. Cappugi, "Giant exophytic basal cell carcinoma treated with radiotherapy," Journal of the European Academy of Dermatology and Venereology, vol. 16, no. 4, pp. 374-376, 2002. 
2. Fattah, J. Pollock, A. Maheshwar, and J. A. Britto, "Big Bad BCCs: craniofacial resection and reconstruction for atypical basal cell carcinoma," Journal of Plastic, Reconstructive and Aesthetic Surgery, vol. 63, pp. e433-e441, 2009.

3. Asilian and B. Tamizifar, "Aggressive and neglected basal cell carcinoma," Dermatologic Surgery, vol. 31, no. 11, pp. 1468-1471, 2005.

4. D. Ozgediz, E. B. Smith, J. Zheng, J. Otero, Z. L. Tabatabai, and C. U. Corvera, "Basal cell carcinoma does metastasize," Dermatology Online Journal, vol. 14, no. 8, article no. 5, 2008.

5. Berking, B. Konz, W. Pfützner, and M. Heckmann, "Giant mutilating basal cell carcinoma of the trunk - a neglected tumor," Hautarzt, vol. 49, no. 9, pp. 719721, 1998.

6. Blum, C. U. Brand, U. Ellwanger et al., "Awareness and early detection of cutaneous melanoma: an analysis of factors related to delay in treatment," British Journal of Dermatology, vol. 141, no. 5, pp. 783-787, 1999.

7. V. R. Doherty, "Why are there delays in patients presenting with melanoma?" British Journal of Dermatology, vol. 141, no. 5, pp. 780-782, 1999. 